\title{
THIN TEFLON-LIKE FILMS FOR ELIMINATING ADHESION IN RELEASED POLYSILICON MICROSTRUCTURES
}

\author{
Bradley K. Smith*, Jeffry J. Sniegowski*, and Glenn LaVigne* \\ *Sandia National Laboratories, Albuquerque, NM 87185
}

\section{SUMMARY}

This paper presents a method for depositing thin Teflon-like films using a commercial plasma reactor to eliminate adhesion or stiction in released polysilicon microstructures. A Lam 384T oxide etch system is used in a remote plasma mode with commercially available trifluoromethane $\left(\mathrm{CHF}_{3}\right)$ to deposit thin hydrophobic films around and under released microstructures. Hard, uniform, Teflon-like films which penetrate into undercuts beneath structures have been produced. Thus far, surfaces beneath gears as large as 1600 micron diameter with a gap of 2.0 microns are hydrophobic after being exposed to plasma treatment. These Teflon-like coatings have been shown to reduce the coefficient of friction from 1.0 to 0.07 .

Key words: Stiction, Microstructures, fluorocarbon.

\section{INTRODUCTION}

Adhesion of microstructures or "stiction" is a prevalent failure mechanism for surface micromachined devices. Several methods are being employed in an effort to eliminate stiction during and after the sacrificial release [1-4]. If the surface of the microstructure remains hydrophilic, capillary condensation of water can occur in narrow contact gaps, even in reduced humidity environments. The condensation generates capillary pressure that can pull surfaces into contact causing adhesion or stiction in devices that were initially free. If the contact angle, $\theta_{\mathrm{c}}$, of the droplet on the surface is $<90^{\circ}$, then the capillary pressure is attractive and the surfaces are pulled into contact. If on the other hand $\theta_{c}>90^{\circ}$, the capillary pressure is repulsive and no surface contact occurs [1]. To alter the contact angle, $\theta_{c}$, it is necessary to modify the surface by depositing a material with a different surface energy. To make the surface hydrophobic, $\theta_{c}>90^{\circ}$, low surface energy coatings are required.

There are several approaches for modifying the surface energy of a microdevice. One technique involves the use of ordered monolayer-thick films referred to as selfassembled monolayers, SAM's [4]. Since these films are only a monolayer thick, they are not as desirable for applications where surfaces come into repeated contact or continuous sliding contact. For thicker films, plasma polymerized fluorocarbons, which resemble pTFE (Teflon), have many good qualities such as they are very hydrophobic $\left(\theta_{c} \approx 109^{\circ}\right)$, smooth and durable[1]. Plasma deposited films have the added flexibility of controllable film thickness when compared to the self-assembled monolayer (SAM) approach [4].

When a fluorocarbon gas is placed into a plasma reactor, the gas is fractured into a "plasma soup" of ions, excited molecules, and radicals. Depending upon the feed gases, substrates exposed to the plasma can be etched or have a polymeric film deposited on them. For this application, the interest is plasma polymerization which has been thoroughly studied [1]. Polymerized tetrafluoroethylene \{pTFE, $\left(\mathrm{CF}_{2}\right)_{\mathrm{x}}$ \} can be grown provided the fluorine-tocarbon ratio of the feed gas is $\mathrm{F} / \mathrm{C} \approx 2$ [1]. If the substrate is placed directly on the cathode or anode of the plasma reactor, ionized species will be accelerated from the plasma to the substrate and will impinge on the substrate normal to the surface. Ion impingement coupled with the short diffusion length of the plasma will cause the fluorocarbon film to deposit anisotropically [1], with the majority of the deposit being line of sight to the plasma. To make the film growth more conformal and likely to penetrate beneath microstructures, the substrate needs to be in a shielded, fieldfree zone adjacent to the plasma [1]. Fluorocarbon films deposited in field free zones within plasmas have been studied by several researchers [1-3]. These studies have shown improved film quality and conformality.

This work furthers the efforts of P.F. Man, B.P. Gogoi, and C.H. Mastrangelo [1] presented at MEMS 96. Man et al. used a Faraday cage containing the wafer placed directly into the plasma region of the reactor. The Faraday cage shields the wafer from ion impingement. Although effective for producing a field free zone, this technique is difficult to automate. We chose to use a reactor easily configured for remote plasma operation and a feed gas $\left(\mathrm{CHF}_{3}\right)$ more commercially available than decafluorobutane $\left(\mathrm{C}_{4} \mathrm{~F}_{10}\right)$. Deposition rates, nonuniformities, film conformality and contact angles are presented. Studies of friction, wear, and stiction have been carried out on Sandia designed and fabricated microengines [5].

\section{EXPERIMENTS}

\section{a) Experimental Apparatus:}

The Lam Research 384T etch system is a triode design, Figure 1, whereby either the lower electrode, upper electrode, or both can be powered. The etcher is configured for $150 \mathrm{~mm}(6 \mathrm{in}$ ) silicon wafers. A single $13.56 \mathrm{Mhz}$ power supply with a matching network directs power to the

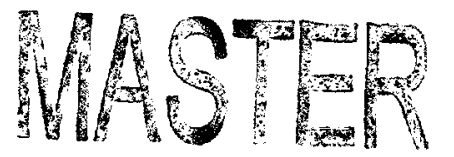




\section{DISCLAIMER}

This report was prepared as an account of work sponsored by an agency of the United States Government. Neither the United States Government nor any agency thereof, nor any of their employees, make any warranty, express or implied, or assumes any legal liability or responsibility for the accuracy, completeness, or usefulness of any information, apparatus, product, or process disclosed, or represents that its use would not infringe privately owned rights. Reference herein to any specific commercial product, process, or service by trade name, trademark, manufacturer, or otherwise does not necessarily constitute or imply its endorsement, recommendation, or favoring by the United States Government or any agency thereof. The views and opinions of authors expressed herein do not necessarily state or reflect those of the United States Government or any agency thereof. 


\section{DISCLAMERR}

Portions of this document may be illegible in electronic image products. Images are produced from the best available original document. 


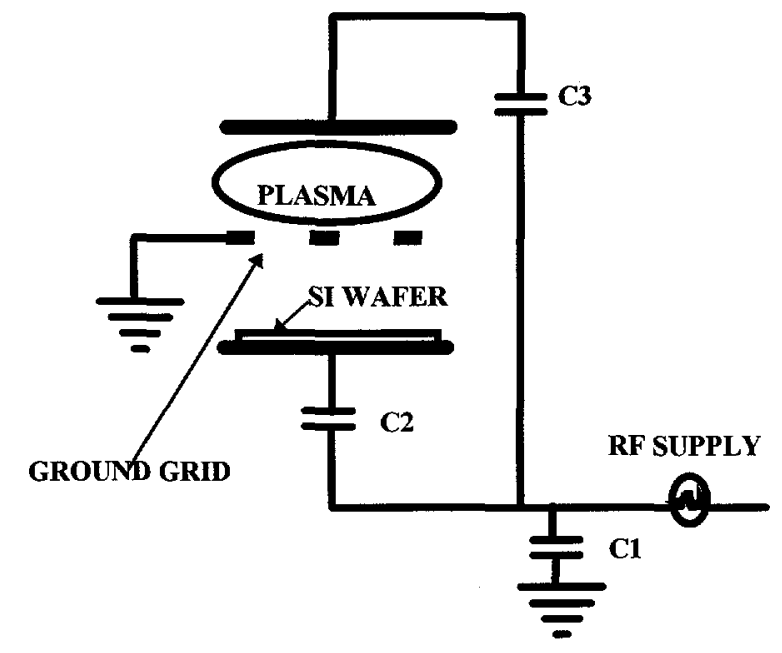

C1, C2, C3 ARE BLOCKING CAPACITORS

Figure 1: Lam 384T Triode Etcher Schematic

electrodes. The electrodes are separated by a grounded diffuser plate that allows gas transport between the upper and lower areas. When the lower electrode is powered, the system operates as a conventional reactive ion etcher. When the upper electrode is powered, the plasma is confined to the region between the upper electrode and ground grid, referred to as "remote plasma mode". In the remote mode, the substrate or wafer is shielded from ion bombardment, but free radicals and neutral species can be readily transported to the wafer surface. The wafer is placed on the lower electrode or cathode and clamped in place with a quartz ring. The wafer is maintained at constant temperature with helium cooling on the back side of the wafer. For these experiments, trifluoromethane $\left(\mathrm{CHF}_{3}\right)$ is used as a monomer source. Though $\mathrm{CHF}_{3}$ has a $\mathrm{F} / \mathrm{C}=3$, which is higher than the recommended value of 2 , it is still easy to deposit plasmapolymerized coatings in the Lam $384 \mathrm{~T}$ system. The presence of hydrogen modifies the $\mathrm{F} / \mathrm{C}$ ratio by recombining with much of the fluorine producing $\mathrm{HF}$. In this way the $\mathrm{F} / \mathrm{C}$ ratio is held close to 2 to 1 .

Film thickness and index of refraction were measured with a Rudolph Focus III ellipsometer and contact angles were obtained with a VCA 2000 Video Contact Angle Measurement System.

\section{b) Deposition rates and Nonuniformities}

Statistical experiment designs were used to explore the parameter space and quickly locate a desirable operating region. For the first design, the RF power was varied (100$800 \mathrm{~W}$ ), pressure $(100-2500 \mathrm{mT})$, and $\mathrm{CHF}_{3}$ flow rate $(100-$ $200 \mathrm{sccm}$ ). Wafer temperature was held constant at $18 \mathrm{C}$. Deposition rates and nonuniformities were measured on bare silicon wafers. We quickly discovered that very high pressure $(2500 \mathrm{mT})$ produces a film with a "soot-like", powdery qualify. Consequently, the experimental matrix was redesigned to restrict the pressure to $500 \mathrm{mT}$, which is in a process region that produces hard, smooth films. Analysis of the first design indicated that the best film uniformity is obtained at low power and high pressure $(100 \mathrm{~W}$ and500mT). The flow rate of $\mathrm{CHF}_{3}$ was not found to have much effect

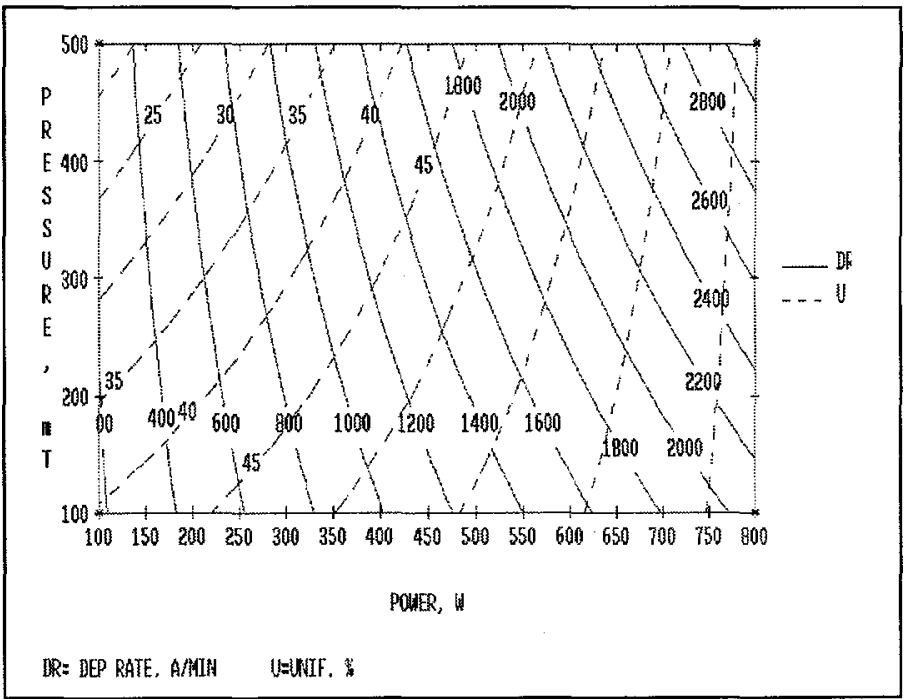

Figure 2: Contour Plot of Deposition Rate and Uniformity.

and was fixed at $200 \mathrm{sccm}$. A contour plot illustrating the deposition rate $(\AA / \mathrm{min})$ and nonuniformity $(\%$,defined as range $/ 2 *$ mean) is shown in Figure 2

A second experiment design was used to further refine the operating space. Power $(100-300 \mathrm{~W})$ and pressure (300-700 mT) were varied, while keeping the $\mathrm{CHF}_{3}$ flow fixed at $200 \mathrm{sccm}$. The second design confirmed that the film uniformity improves as the pressure is increased, while the keeping the power low. Film quality remains hard and smooth at $700 \mathrm{mT}$, so the onset of the powdery deposit occurs at a pressure somewhere above $700 \mathrm{mT}$. The deposition rate is dominated by RF power. Tradeoffs with the processing conditions are required to achieve both a reasonable nonuniformity and deposition rate. We choose to operate at $500 \mathrm{mT}, 200 \mathrm{~W}$, and $200 \mathrm{sccm} \mathrm{CHF}_{3}$, which produces a nonuniformity of $\sim 25 \%$ with a deposition rate between 300 and $400 \AA / \mathrm{min}$. Results of the second design are presented in Figure 3. The nonuniformity rapidly worsens towards the edge of the wafer. If the outer $20 \mathrm{~mm}$ of the wafer radius is excluded, the nonuniformity improves to $4 \%$.

\section{c) Film Conformality and Properties}

Film thickness falls off rapidly in the undercuts beneath polysilicon structures, Figure 4. Still, there is sufficient film deposition in the undercuts to make the surface hydrophobic. These films have the ability to penetrate a $2 \mu \mathrm{m}$ gap with a $800 \mu \mathrm{m}$ undercut. To confirm the presence of polymer beneath large microdevices, the structures are removed using adhesive tape following a deposition. The contact angle is then measured with water in the area which 


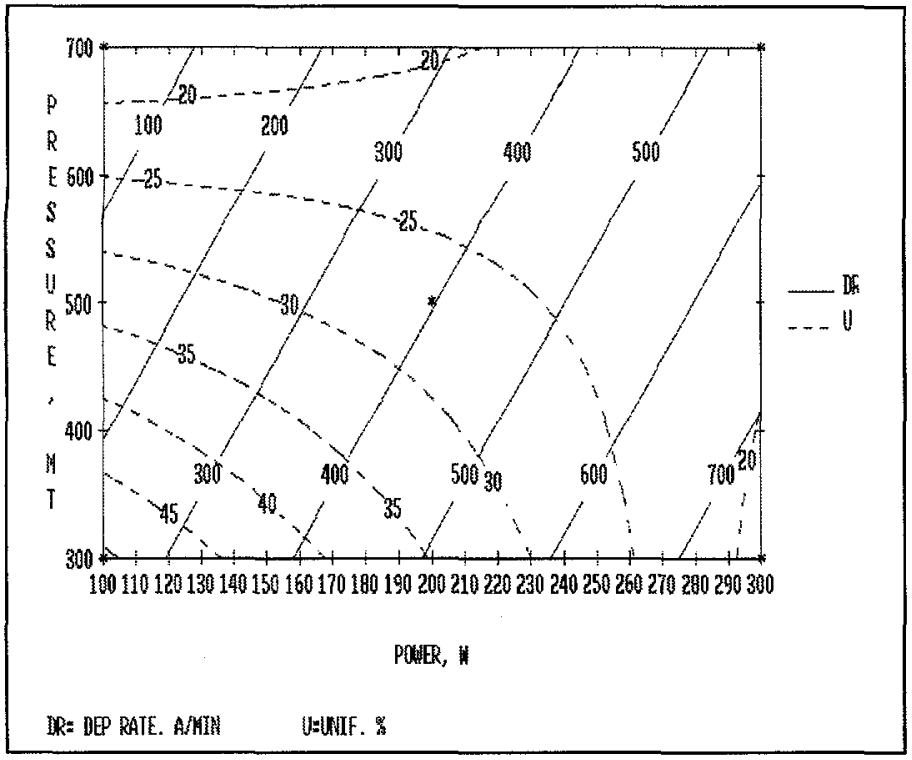

Figure 3: Contour Plot for Second Experimental Design

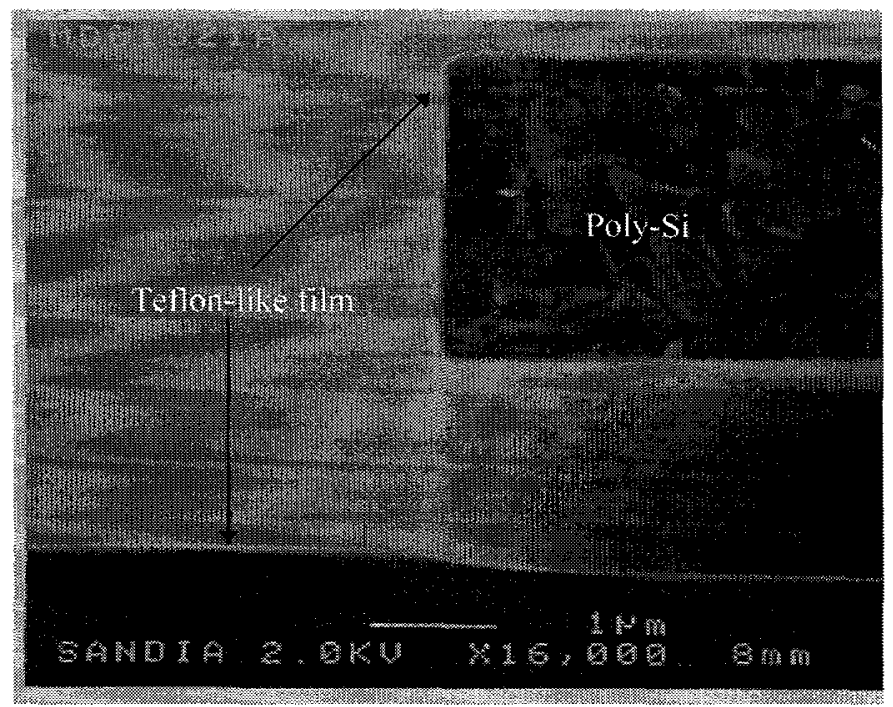

Figure 4. Teflon-Like Film Deposition into Undercut

is directly beneath where the structure was located. Contact angle measurements of $108^{\circ}$ show the surfaces to be hydrophobic confirming the presence of polymer. For comparison purposes, the contact angle underneath structures on uncoated wafers was $61^{\circ}$ (hydrophilic). From the contact angle study, it is apparent that the film is depositing deeply into the undercut regions, but attempts to accurately determine the film thickness by ellipsometry have been unsuccessful to date.

For all deposition conditions, the contact angle and refractive index were found to be relatively constant at $108^{\circ}$ (std. dev. $=2.8^{\circ}$ ) and 1.4 (std. dev. $=0.01$ ), respectively. From these measurements, we surmised that the film quality does not vary much under the conditions investigated in this study. The refractive index and contact angle indicate the film is very similar to bulk Teflon pTFE, and of comparable quality to those reported elsewhere [1-3].
It was discovered that these Teflon-like films are readily removed with oxygen plasmas, and could be patterned using a suitable masking material. After stripping the Teflon-like film, the contact angle measures $45^{\circ}$, which is comparable to those prior to exposure.

\section{d) Friction Measurements}

Although plasma-deposited fluorocarbon films have been shown to reduce or eliminate post-release stiction and are durable under repeated contact of coated surfaces [1], their impact on friction under continual sliding contact is not known. Sliding friction is of significant interest in the case of the Sandia microengine and geared micromechanisms as shown in Figure 5 where the rotating elements are supported by journal-type bearings. We have begun a series of experiments to investigate the effect of the fluorocarbon films on the coefficient of friction (cof) and wear lifetime in such mechanisms. The approach is based on the analysis of friction in the microengine by Miller et al. [6]. The method involves the acquisition of gear position versus time data (as shown in Figure 6) under the influence of specified drive signal to the microengine. By matching the model, which includes the effect of friction, a coefficient of friction is extracted.

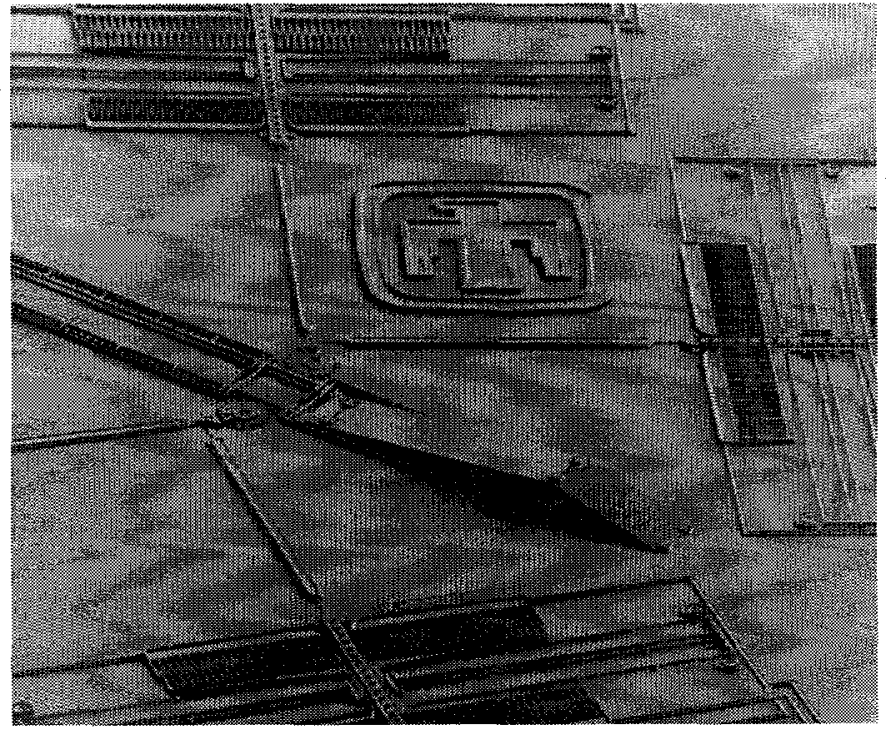

Figure 5: Sandia Microengine positioning a mirror

Preliminary experiments investigated the film deposited at $500 \mathrm{mT}, 200 \mathrm{~W}$, and $200 \mathrm{sccm} \mathrm{CHF}_{3}$ for several thicknesses of deposition. An initial observation is that film thicknesses greater than approximately $1000 \AA$ provided enough material in the bearing areas to interfere with normal device operation. Therefore, film depositions in the range of 100 to $500 \AA$ are analyzed. Figure 7 is an example of the data taken on a microengine coated with $200 \AA$ of fluorocarbon film and operated for 30 minutes at 15,000 revolutions per minute. Following the method of Miller et al [6] the first $90^{\circ}$ of rotation where the model is most accurate, is used to extract a coefficient of friction of 0.07 . This coefficient of friction corresponds well with that typically observed for 
bulk Teflon on Teflon (cof $=0.04$ )[7]. The overall effect of the fluorocarbon film to date is a definite improvement in the behavior of the microengine relative to an engine

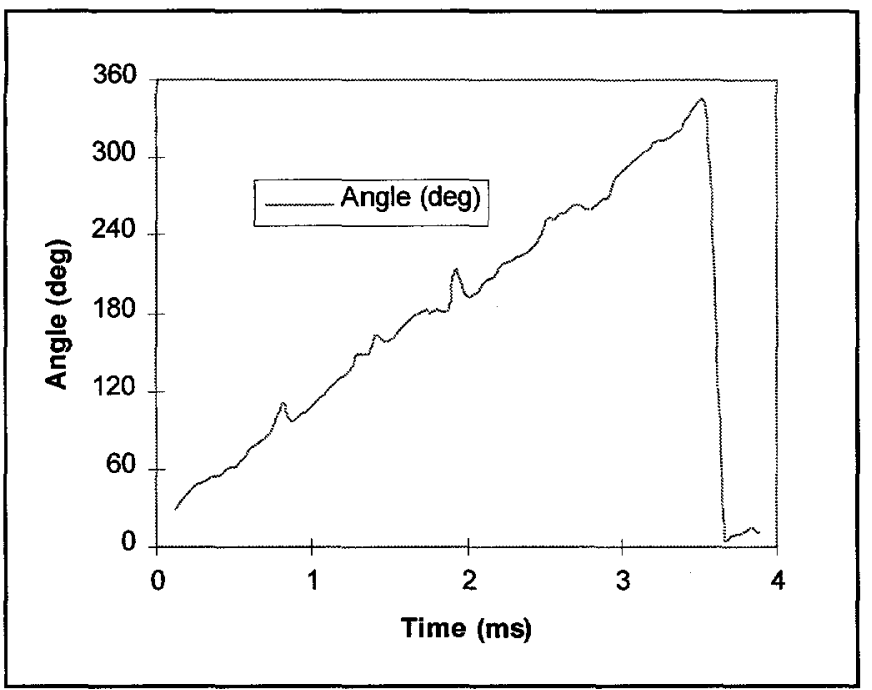

Figure 6: Gear Position versus Time

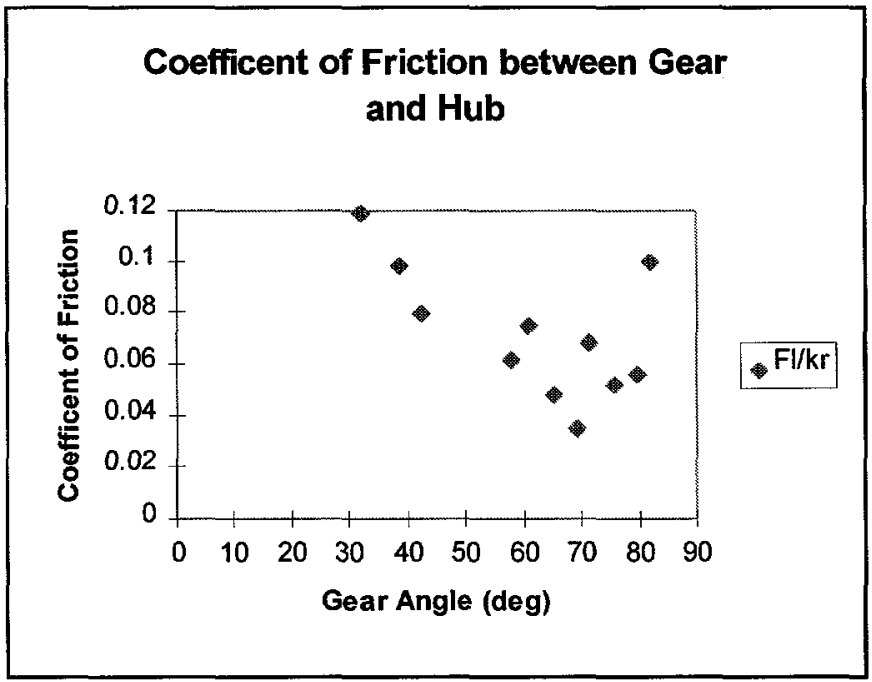

Figure 7: Coefficient of Friction versus Angle

which has no coatings of any type, i.e. polysilicon-topolysilicon contact ( $c o f=0.7-1.0$ ). For engines with a SAM coating of octadecyltrichlorosilane, ODTS [8], the cof of 0.08 is nearly identical to that of the fluorocarbon film.

No definitive conclusion has been drawn regarding the affect on operational lifetime at this time.

\section{CONCLUSIONS}

Teflon-like films can be readily deposited on microstructures using the Lam 384T oxide etch system utilizing $\mathrm{CHF}_{3}$ as the polymer precursor. Film properties, such as contact angle with water and index of refraction, are constant over a wide range of processing conditions. The films are very hydrophobic and have the ability to penetrate into narrow openings beneath microstructures. Film properties are comparable with those of bulk Teflon. The cof for these
Teflon-like films is nearly identical with SAM coatings and are only slightly higher than bulk Teflon. The cof is reduced by an order of magnitude when compared to microstructures with no friction reducing coating.

\section{ACKNOWLEDGEMENTS}

The efforts of Steve Chang, Amie Glenzinski, and Peggy Clews, Sandia National Laboratories are gratefully acknowledged in helping with sample preparation.

This work was supported by the United States Department of Energy under Contract DE-AC04-94AL85000. Sandia is a multiprogram laboratory operated by Sandia Corporation, a Lockheed Martin Company, for the United States Department of Energy.

\section{REFERENCES:}

1. P.F. Man, B.P. Gogoi, and C.H. Mastrangelo, "Elimination of Post-Release Adhesion in Microstructures Using Thin Conformal Fluorocarbon Films", Micro ElectroMechanical Systems 96, pp 55-60.

2. P.D. Buzzard, "Plasma Polymerization of Tetrafluoroethylene in a Field Free Zone", Master's Thesis, University of California, Berkeley, 1978.

3. H.V. Jansen, J.G.E. Gardeniers, J. Elders, H.A.C. Tilmans and M. Elwenspoek,"Applications of fluorocarbon polymers in micromechanics and micromachining", Sensors and Actuators A, 41-42 (1994), pp 136-140.

4. M.R. Houston, R Maboudian, and R.T. Howe, "SelfAssembled Monolayer Films as Durable Anti-Stiction Coatings for Polysilicon Microstructures", 1996 SolidState Sensor and Actuator Workshop, pp 42-47.

5. J.J. Sniegowski, S.L. Miller, G.F. LaVigne, M.S. Rodgers and P.J. McWhorter, "Monolithic Geared-Mechanisms Driven by a Polysilicon Surface-Micromachined On-Chip Electrostatic Microengine", 1996 Solid-State Sensor and Actuator Workshop, pp 178-182.

6. S. Miller, J. J. Sniegowski, G. LaVigne, and P. J. McWhorter, "Friction in Surface Micromachined Microengines", Proc. SPIE Smart Electronics and MEMS Vol 2722, San Diego, Feb. 28-29, 1996, pp 197-204.

7. Handbook of Chemistry and Physics, CRC Press, 1977, pp F-21.

8. Sandia Internal Correspondence, 1996. 